\title{
Synapse Formation between Central Neurons Requires Postsynaptic Expression of the MEN1 Tumor Suppressor Gene
}

\author{
Ronald E. van Kesteren, ${ }^{1}$ Naweed I. Syed, ${ }^{2}$ David W. Munno, ${ }^{2}$ Jildau Bouwman, ${ }^{1}$ Zhong-Ping Feng, ${ }^{2}$ \\ Wijnand P. M. Geraerts, ${ }^{1}$ and August B. Smit ${ }^{1}$ \\ ${ }^{1}$ Department of Molecular and Cellular Neurobiology, Research Institute Neurosciences, Vrije Universiteit, 1081HV \\ Amsterdam, The Netherlands, and ${ }^{2}$ Respiratory and Neuroscience Research Groups, Faculty of Medicine, University of \\ Calgary, Alberta, Canada T2N 4N1
}

Synapse formation is a crucial step in the development of neuronal circuits and requires precise coordination of presynaptic and postsynaptic activities. However, molecular mechanisms that control the formation of functionally mature synaptic contacts, in particular between central neurons, remain poorly understood. To identify genes that are involved in the formation of central synapses, we made use of molluscan neurons that in culture form synaptic contacts between their somata (somasoma synapses) in the absence of neurite outgrowth. Using single-cell mRNA differential display, we have identified a molluscan homolog of the multiple endocrine neoplasia type 1 (MEN1) tumor suppressor gene encoding the transcription fac- tor menin as a gene that is upregulated during synapse formation. In vitro antisense knock-down of MEN1 mRNA blocks the formation of mature synapses between different types of identified central neurons. Moreover, immunocytochemistry and cell-specific knock-down of MEN1 mRNA show that postsynaptic but not presynaptic expression is required for synapses to form. Together, our data demonstrate that menin is a synaptogenic factor that is critically involved in a general postsynaptic mechanism of synapse formation between central neurons.

Key words: synaptogenesis; soma-soma synapse; gene expression; MEN1 tumor suppressor gene; menin; transcription factor; antisense knock-down
All functions of the nervous system critically depend on the formation of organized neuronal networks during development. A crucial step in this process is the formation of specific synapses between presynaptic and postsynaptic neurons. Molecular mechanisms that control synapse formation remain poorly understood, and most of our knowledge comes from studies on the neuromuscular junction (NMJ). These studies show that developing presynaptic and postsynaptic cells exchange signals that coordinate their mutual maturation, involving both the recruitment of preexisting proteins and the induction of new gene expression (Sanes and Lichtman, 1999). The same mechanisms play a role in the formation of central synapses, and recent investigations have started to shed light on the proteins and genes involved. For instance, Wnt factors (Hall et al., 2000) and neuroligin (Scheiffele et al., 2000) induce presynaptic differentiation at cerebellar granule cell synapses, whereas postsynaptic differentiation is controlled by presynaptically released neuregulin (Ozaki et al., 1997), and in Caenorhabditis elegans, the intracellular presynaptic protein regulator of presynaptic morphology-1 controls the formation of central synapses (Schaefer et al., 2000).

These recent findings have raised the question as to how these

\footnotetext{
Received Jan. 8, 2001; revised June 4, 2001; accepted June 6, 2001.

This work was supported by the Royal Dutch Academy of Sciences, by Grant RG0045/1997B from the Human Frontier Science Program Organization, and by the Medical Research Council (MRC) of Canada. N.I.S. is an Alberta Heritage Foundation for Medical Research (AHFMR) senior scholar and was supported by Visitors Grant B88-236 from the Netherlands Foundation for Scientific Research. D.W.M. and Z.-P.F. were supported by AHFMR and MRC/Alberta Lung Association studentships, respectively.

GenBank accession number for the $L-M E N 1$ gene: AF395538.

Correspondence should be addressed to Dr. R. E. van Kesteren, Department of Molecular and Cellular Neurobiology, Faculty of Biology, De Boelelaan 1087, 1081HV Amsterdam, The Netherlands. E-mail: revankes@bio.vu.nl.

Copyright (C) 2001 Society for Neuroscience $0270-6474 / 01 / 210001-05 \$ 15.00 / 0$
}

different molecules act together and which genes are upstream and downstream of them, thus defining the molecular pathways that lead to synapse formation (Chang and Balice-Gordon, 2000). Whereas downstream elements may encode previously established synaptic proteins that are directly involved in synaptic transmission and plasticity, upstream elements may include transcription factors that coordinate the proper temporal expression patterns of synaptogenesis-associated proteins. At the developing NMJ, ETS family (Schaeffer et al., 1998) and MyoD family (Rudnicki and Jaenisch, 1995) transcription factors and cAMP response element-binding protein (CREB)-binding protein (Marek et al., 2000) play a role, and at interneuronal synapses, the ETS transcription factor ER81 recently has been shown to control synapse formation (Arber et al., 2000). Here, we have identified the molluscan homolog of the transcription factor menin, the product of the multiple endocrine neoplasia type 1 (MEN1) tumor suppressor gene (Chandrasekharappa et al., 1997), as a critical mediator of synapse formation between central neurons. We show that postsynaptic expression of menin is necessary for the proper formation of various types of central synapses, both

This article is published in The Journal of Neuroscience, Rapid Communications Section, which publishes brief, peerreviewed papers online, not in print. Rapid Communications are posted online approximately one month earlier than they would appear if printed. They are listed in the Table of Contents of the next open issue of JNeurosci. Cite this article as: JNeurosci, 2001, 21:RC161 (1-5). The publication date is the date of posting online at www.jneurosci.org.

http://www.jneurosci.org/cgi/content/full/5549 
excitatory and inhibitory. This finding opens up the possibility of studying the underlying gene program that coordinates postsynaptic aspects of central synapse formation.

\section{MATERIALS AND METHODS}

Animals. Laboratory-raised stocks of Lymnaea stagnalis were maintained at room temperature and fed lettuce. Snails with a shell length of 18-20 mm (1-2 months old) were used for cell isolations; snails with a shell length of 20-25 mm (2-3 months old) were used to produce brainconditioned medium (CM).

Cell culture. Animals were dissected under sterile conditions as described previously (Syed et al., 1990). Brains were washed with antibiotic saline $(50 \mu \mathrm{g} / \mathrm{ml}$ gentamycin). To prepare $\mathrm{CM}$, gentamycin-treated brains were incubated in defined medium (serum-free $50 \%$ L-15 medium; Life Technologies, Rockville, MD) as described previously (Wong et al., 1981). For cell isolation, gentamicin-treated brains were incubated in a $0.3 \%$ trypsin-collagenase-dispase solution and pinned down to the bottom of the dissection dish (Syed et al., 1990). Sigmacote (Sigma, St. Louis, MO)-treated, fire-polished glass pipettes were used to extract neurons, which were subsequently plated onto poly-L-lysine-pretreated coverslips in the presence of CM and incubated overnight. Soma-soma synapses were constructed as described previously (Feng et al., 1997).

Electrophysiology. Intracellular recordings were used to monitor synaptic activity (Syed and Winlow, 1991). Glass microelectrodes (1.5-2.0 $\mu \mathrm{m}$ internal diameter; World Precision Instruments, Sarasota, FL) were filled with a saturated solution of $\mathrm{K}_{2} \mathrm{SO}_{4}$ (resistance, 20-40 M $\Omega$ ). Neurons were observed under an inverted microscope (Axiovert 135; Zeiss, Esslingen, Germany) and impaled using Narashige (Tokyo, Japan) micromanipulators (MM 202 and MM 204). Electrical signals were amplified using a NeuroData amplifier, displayed on a PM 3394 digital oscilloscope (Philips, Eindhoven, The Netherlands), and recorded on a TA 240S chart recorder (Gould, Cleveland, $\mathrm{OH}$ ).

Differential display-PCR. Differential display PCRs (DD-PCRs) were performed on triplicates of soma-soma-paired neurons and unpaired control neurons as described previously (Van Minnen and van Kesteren, 1999). Differentially expressed cDNAs were isolated, cloned in pGEM-T or in pBluescript, sequenced, and compared on-line with GenBank nonredundant database entries using the BLASTN and BLASTX algorithms (Altschul et al., 1990).

Full-length cDNA cloning of L-MEN1. Sense and antisense primers were designed based on the sequence of the $300 \mathrm{bp}$ L-MEN1 DD-PCR product and used to PCR-screen Lymnaea brain-specific cDNA libraries in combination with vector-based primers. One clone was amplified that appeared to contain the complete ORF and sequenced on both strands from three independent amplifications. Because this cDNA contained only three nucleotides of $5^{\prime}$ untranslated region (UTR) before the predicted start codon and because no larger cDNAs were found in our libraries, we obtained an additional $425 \mathrm{bp}$ of $5^{\prime}$ UTR by performing $5^{\prime}$ rapid amplification of cDNA ends on Lymnaea brain mRNA.

Anitisense knock-down experiments. Soma-soma synapses were prepared as described above. Initially, cells were paired in CM containing either $15 \mu \mathrm{M} L$-MEN1 antisense oligonucleotide (5'-AAAGGCCGGCAACTT-3') or $15 \mu \mathrm{M}$ mismatch oligonucleotide (5'-AAAGCCCGCCATCTT-3'). The following day, cells were monitored for outgrowth by light microscopy; synaptic activity was monitored electrophysiologically as described above. For selective antisense knock-down experiments, cells were isolated and plated individually in hemolymph-coated dishes to prevent neuronal adhesion to the substrate (Syed et al., 1996). After overnight incubation in CM containing either antisense or mismatch oligonucleotides, cells were paired in poly-L-lysine-coated dishes. Soma-soma pairs were prepared between mismatch-treated presynaptic and postsynaptic cells (controls), between mismatch-treated presynaptic and antisensetreated postsynaptic cells (postsynaptic knock-downs), and vice versa (presynaptic knock-downs). Electrophysiological recordings were made 5-7 hr later.

Western blotting and immunocytochemistry. An antiserum was raised in mice against a synthetic peptide corresponding to amino acids 181-194 of L-menin (TAEVTWHGKGNED). This polyclonal antiserum was tested on a Western blot containing Lymnaea total brain extract to check for specificity and was then used to immunocytochemically stain somasoma-paired Lymnaea neurons. Preimmune serum was used as a negative control. Cells were fixed in $4 \%$ paraformaldehyde, permeabilized in $0.5 \% \mathrm{NP}-40$, incubated for $4 \mathrm{hr}$ in primary antiserum diluted 1:500 in 1\% Boehringer blocking reagent (BBR) (Boehringer Mannheim, Mannheim,
Germany), and incubated for $1 \mathrm{hr}$ in secondary antibody (rabbit antimouse coupled to horseradish peroxidase or alkaline phosphatase) diluted 1:2000 in 1\% BBR. Between each step, cells were washed with PBS. Antibody binding was visualized using the appropriate enzyme substrate.

\section{RESULTS}

To identify genes involved in synapse formation, we made use of an in vitro preparation of identified presynaptic and postsynaptic central neurons of the mollusk L. stagnalis. These neurons can be individually isolated from the adult brain, and when juxtaposed in culture in a soma-soma configuration, they readily reform neuron-specific synaptic connections that are functionally indistinguishable from synapses in the intact brain (Feng et al., 1997). The principle advantage of soma-soma-paired cells is that they do not display neurite outgrowth (Feng et al., 2000), allowing the identification of genes that are specifically involved in synapse formation. We used a single-cell mRNA differential display technique (DD-PCR) to characterize changes in gene expression that occur during soma-soma pairing of two identified Lymnaea neurons [i.e., the right pedal dorsal 1 (RPeD1) and visceral dorsal 4 (VD4) neurons]. When plated in CM (Wong et al., 1981), the soma-soma-paired cells RPeD1 and VD4 form a characteristic bidirectional inhibitory synaptic contact within $16 \mathrm{hr}$ (Feng et al., 1997). Cells plated individually (unpaired) in the same dish were used as controls. One of the genes that was found by DD-PCR to be expressed in soma-soma-paired cells but not in unpaired cells (Fig. $1 A$ ) is the Lymnaea homolog of the human MEN1 gene (Chandrasekharappa et al., 1997), named here L-MEN1 (Fig. 1B).

The MEN1 gene was first identified as a tumor suppressor gene (Chandrasekharappa et al., 1997). MEN1 orthologs were subsequently identified in rodents (Stewart et al., 1998; Maruyama et al., 1999), zebrafish (Khodaei et al., 1999), and Drosophila (Maruyama et al., 2000; Guru et al., 2001). The human MEN1 gene product, a protein named menin, contains two basic nuclear localization signals that cause it to translocate to the nucleus (Guru et al., 1998). The L-MEN1 gene product, here named L-menin, is a 759 amino acid protein, almost 150 amino acids larger than its vertebrate counterparts (Fig. 1B). L-menin and human menin share $49 \%$ sequence identity, most of which is located in the N-terminal part (amino acids 1-420) and in the most C-terminal part of the protein (amino acids 695-759; all amino acid positions refer to the L-menin sequence). Two nuclear localization signals are present at conserved positions in L-menin [i.e., RKGQRRR (amino acids 509-515) and RKRPRR (amino acids 751-756)], and there is one unique nuclear localization signal [i.e., RKRRYK (amino acids 318-323)] (Fig. 1B), suggesting that L-menin is also a nuclear protein. Moreover, nuclear localization of L-menin is predicted with $70 \%$ confidence using the PSORT algorithm (Nakai and Kanehisa, 1992).

To test whether a causal relationship exists between MEN1 expression and synapse formation in Lymnaea, an antisense knock-down approach was used. We paired Lymnaea neurons in $\mathrm{CM}$ containing an antisense oligonucleotide against the translation initiation site of the $L-M E N 1$ mRNA. Control cells were paired in $\mathrm{CM}$ containing a $3 \mathrm{bp}$ mismatch oligonucleotide. In addition to the inhibitory synaptic pair RPeD1-VD4 (Feng et al., 1997), two excitatory synaptic pairs [i.e., RPeD1-VD2 and VD4left pedal dorsal 1 (LPeD1)] (Hamakawa et al., 1999; Woodin et al., 1999) were also tested. In the presence of the mismatch (control) oligonucleotide, 92\% of the cell pairs tested formed normal synapses $(n=13)$ (Fig. $2 A)$. However, in the presence of the antisense oligonucleotide, $93 \%$ of all pairs failed to develop 


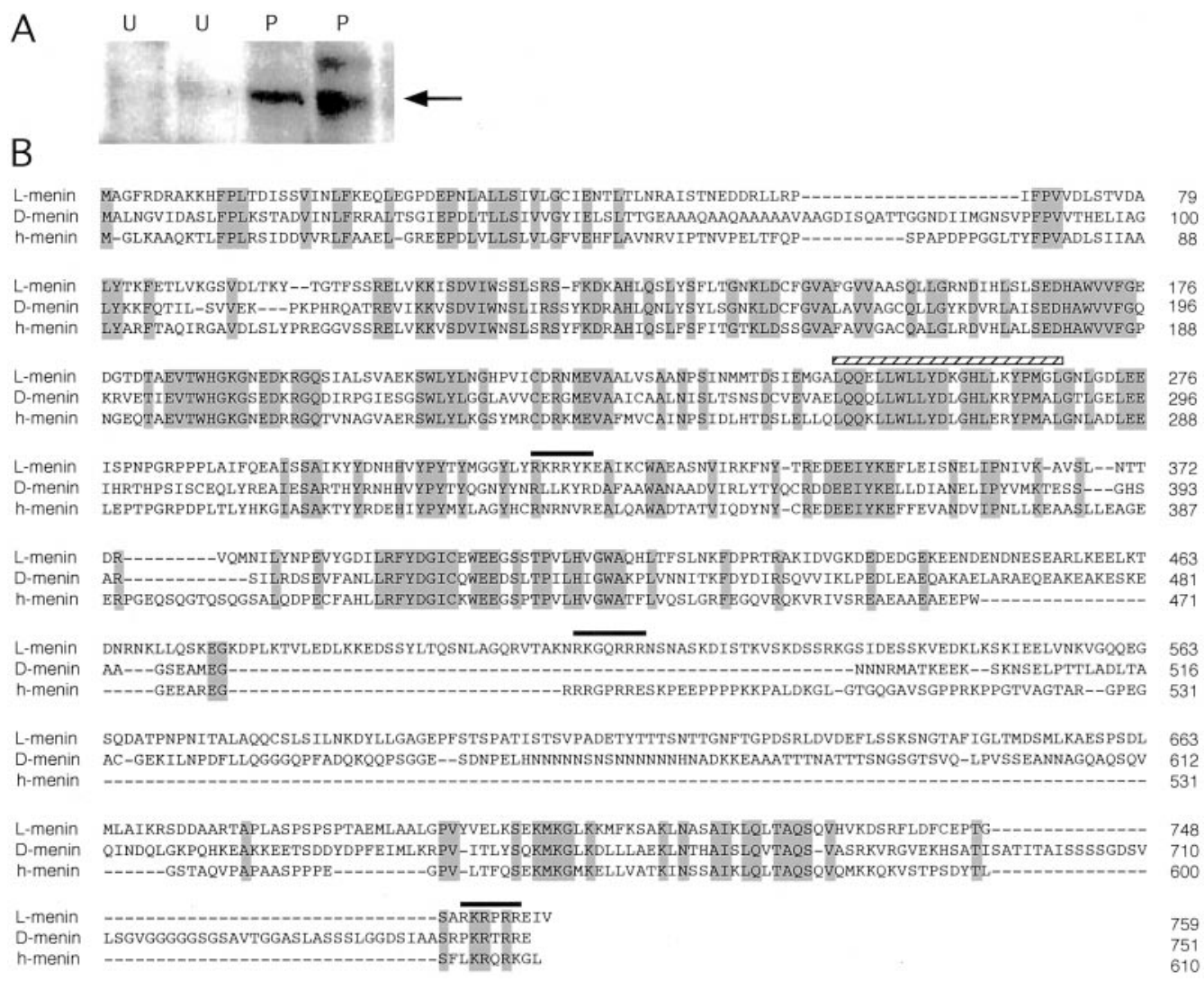

Figure 1. The Lymnaea MEN1 gene is upregulated during synapse formation. A, Differential display gel showing the upregulation of a 300 bp PCR product (arrow) in paired cells $(P)$ compared with unpaired cells $(U)$. B, Amino acid sequence comparison of the $L$-MEN1 gene product, L-menin, with Drosophila menin (D-menin; GenBank accession number AB040816) and human menin (h-menin; GenBank accession number NM000244). Identical amino acids in all three sequences are shaded. Black bars indicate nuclear localization sequences; the hatched bar indicates a conserved leucine zipper motif.

normal synapses $(n=15)$ (Fig. $2 A)$. All cells were viable and showed normal morphology (Fig. $2 B, C$ ). Resting membrane potentials were normal compared with control cells $(59.1 \pm 6.5 \mathrm{mV}$ vs $56.4 \pm 8.8 \mathrm{mV}$ for VD4, which is the most frequently used cell type in our experiments), and evoked spike amplitudes did not differ from controls $(63.7 \pm 6.4 \mathrm{mV}$ vs $59.8 \pm 3.3 \mathrm{mV}$ for VD4). However, neither spontaneous nor induced action potentials generated postsynaptic potentials in $60 \%$ of the inhibitory pairs (Fig. $2 E$ ) and $50 \%$ of the excitatory pairs (Fig. $2 G$ ) in which L-menin expression was knocked down. In all other cases, synaptic transmission was significantly impaired. For instance, in two of four of the bidirectional inhibitory cell pairs (RPeD1-VD4), synaptic transmission was weak and in one direction only (data not shown), whereas in all excitatory pairs (RPeD1-VD2 and LPeD1-VD4) in which synaptic transmission was detectable, the amplitude of the EPSPs was significantly reduced $[1.1 \pm 0.5 \mathrm{mV}$ ( $n=4$ in knock-down pairs) vs $7.1 \pm 3.7 \mathrm{mV}$ ( $n=7$ in control pairs); mean $\pm \mathrm{SD} ; p=0.012$ ] (Fig. $2 H-J$ ). Thus, there is a causal relationship between $L-M E N 1$ expression and the formation of functionally mature synaptic contacts, both inhibitory and excitatory.

Our next aim was to test whether L-menin is specifically involved in either presynaptic or postsynaptic mechanisms of synapse formation. To define the precise locus of L-menin expression, we first stained VD4-LPeD1 soma-soma pairs with an antibody that recognizes the L-menin protein (Fig. $3 A$ ). These data show that L-menin is selectively expressed in the postsyn- aptic cell (Fig. 3B), suggesting a postsynaptic function. The protein seems to be localized specifically in the perinuclear zone, suggesting nuclear translocation. Similar perinuclear staining has been observed for other transcription factors (Ratziu et al., 1998). The failure of our antibody to stain the nucleus itself could be explained by the fact that interaction with other nuclear proteins might mask the epitope. We subsequently prepared soma-soma pairs between presynaptic and postsynaptic cells that were incubated individually in either the antisense or the mismatch oligonucleotides and paired $24 \mathrm{hr}$ later in CM. These experiments revealed that perturbation of $L-M E N 1$ expression in postsynaptic cells $(n=5)$ (Fig. $3 D)$ but not in presynaptic cells $(n=5)$ (Fig. $3 E$ ) blocked synapse formation between paired neurons. Control pairs (presynaptic and postsynaptic cells incubated in mismatch oligonucleotides; $n=5$ ) (Fig. $3 F$ ) always developed normal synaptic contacts. These data demonstrate that L-menin expression is required only in the postsynaptic cell to induce synapse formation.

\section{DISCUSSION}

Our data provide evidence that the transcription factor menin plays a crucial role in a postsynaptic mechanism of central synapse formation. In addition, our findings, together with its previously established role as tumor suppressor, suggest that menin may be part of a common regulatory mechanism for synaptic differentiation and cellular differentiation. Because the cellular actions of menin are for the most part unknown, one can only 

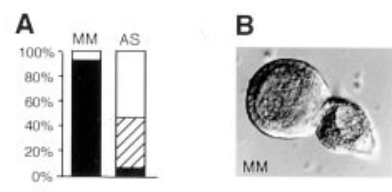

C

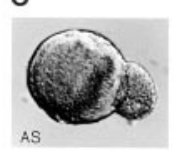

D
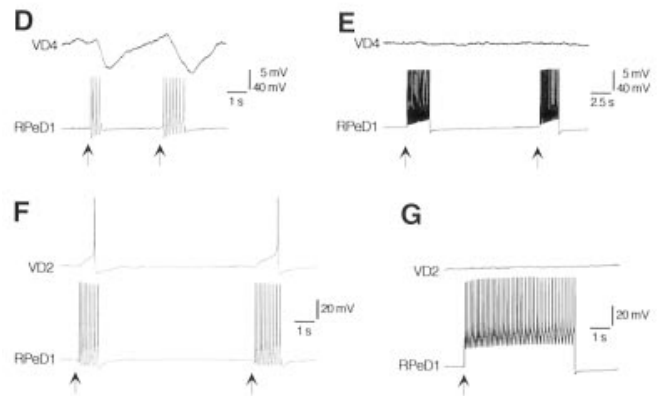

H
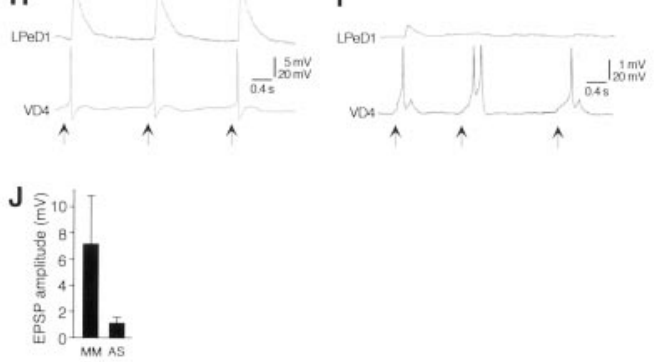

Figure 2. Antisense knock-down of L-menin prevents synapse formation between different types of Lymnaea neurons. A, Antisense knock-down of menin $(A S)$ either prevented synapse formation (open bar) or significantly reduced synaptic efficacy (hatched bar) in $93 \%$ of the cell pairs compared with mismatch-incubated pairs $(M M)$. A black bar represents the number of normal synapses. Cells incubated in antisense oligonucleotides $(B)$ and cells incubated in mismatch oligonucleotides $(C)$ had normal morphology and were comparable with control cells with respect to viability and membrane potential parameters. $D$, Characteristic inhibitory synapse from RPeD1 onto VD4 in cell pairs incubated in the mismatch oligonucleotide, showing compound IPSPs in VD4 after stimulation of RPeD1. $E$, In the knock-down pairs, stimulation of RPeD1 did not produce IPSPs in VD4. $F$, RPeD1-VD2 pairs incubated in mismatch oligonucleotides formed a characteristic excitatory chemical synapse from RPeD1 onto VD2. $G$, In the knock-down pairs, trains of action potentials in RPeD1 failed to induce EPSPs in VD2. $H$, VD4-LPeD1 pairs incubated in mismatch oligonucleotides formed a characteristic excitatory synapse, showing one-for-one EPSPs in LPeD1. EPSPs were consistently generated, as can be observed by comparing three consecutive EPSPs. I, In knock-down pairs, EPSPs could often be generated in LPeD1 with the first presynaptic action potential, but subsequent stimulations failed to produce postsynaptic responses. $J$, The average EPSP amplitude in VD4LPeD1 knock-down pairs was significantly reduced compared with control pairs $[1.1 \pm 0.5 \mathrm{mV}(n=4)$ vs $7.1 \pm 3.7 \mathrm{mV}(n=7)$; mean $\pm \mathrm{SD} ; p=$ 0.012]. Arrows indicate the onset of stimulation.

speculate about the nature of such regulatory pathways. However, menin has been reported to interact with various other transcription factors, including the basic leucine zipper protein JunD (Agarwal et al., 1999) and the TGF- $\beta$-regulated protein Smad3 (Kaji et al., 2001). The interaction with Smad3 is of particular interest in this respect, because TGF- $\beta$ not only acts as a tumor suppressor (Markowitz and Roberts, 1996) but has also been implicated in synaptic plasticity (Zhang et al., 1997). Thus, menin may be part of a common, TGF- $\beta$-induced signaling pathway for both cellular and synaptic differentiation.

Because we identified L-menin in a molecular screen that differentiates between outgrowing and synapse-forming neurons,
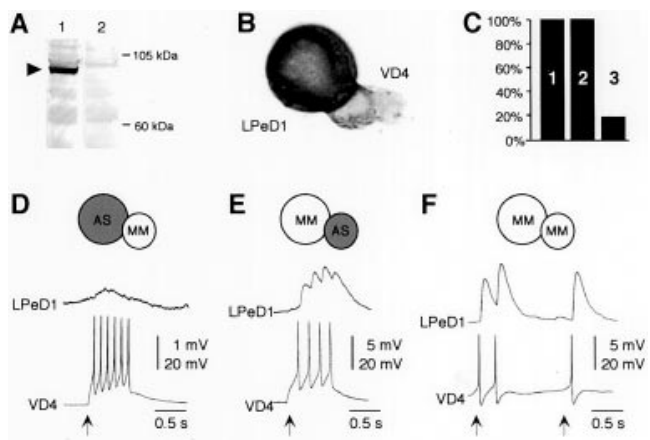

Figure 3. L-menin expression is required postsynaptically for synapse formation to occur. $A$, An antibody directed against L-menin recognizes a protein of the appropriate size $(\sim 85 \mathrm{kDa})$ on a Western blot of Lymnaea total brain extract (lane 1), which is not recognized by the preimmune serum (lane 2). B, Immunostaining of VD4-LPeD1 somasoma pairs identified the postsynaptic cell (LPeD1) as the cell that expresses L-menin. $C$, When L-menin expression was knocked down selectively in either the presynaptic or the postsynaptic cell, synapses formed normally in control pairs (bar 1) and in presynaptic knock-down pairs (bar 2) but failed to form in $80 \%$ of the pairs when menin expression was knocked down in the postsynaptic cell only (bar 3). D, Absence of EPSPs in LPeD1 when L-menin expression is knocked down in LPeD1. $E$, Normal EPSPs in LPeD1 when L-menin expression is knocked down in VD4. F, Normal EPSPs in control pairs in which both cells were incubated in the presence of mismatch oligonucleotides. Arrows indicate the onset of stimulation.

one could question whether L-menin affects synapse formation per se or whether it does so indirectly by suppressing neurite outgrowth. Two observations strongly suggest that L-menin is directly involved. First, the upregulation of L-menin expression is only observed in postsynaptic neurons and not in presynaptic neurons, whereas in both cells neurite outgrowth is suppressed during synapse formation. Second, when $L-M E N 1$ expression was knocked down, we never observed an induction of neurite outgrowth from soma-soma-paired neurons (Fig. 2C). Thus, L-menin most likely controls synapse formation directly, whereas suppression of neurite outgrowth is controlled by a separate mechanism.

Although our knock-down experiments show that synapse formation is abolished in the absence of L-menin, this is not caused by a general effect on the viability and neuronal properties of the cells, because presynaptic neurons do not seem to be affected by $L-M E N 1$ knock-down with respect to membrane potential properties. Moreover, in many instances, postsynaptic potentials could be generated with the first presynaptic action potentials, but subsequent presynaptic spikes failed to produce a response in the postsynaptic cell (Fig. 2I). This demonstrates that cells are in principle capable of chemical transmission, but fail to develop functionally mature synaptic contacts in the absence of L-menin. The latter observation would suggest either a role in the maturation of the postsynaptic element itself or involvement in a retrograde feedback mechanism that induces presynaptic maturation. Interestingly, the latter alternative seems to hold true for another transcriptional regulator, CREB-binding protein, which is required postsynaptically to modulate the transmitter release properties of the presynaptic cell at the Drosophila NMJ (Marek et al., 2000). A candidate factor for the retrograde signal involved could be the transmembrane cell adhesion molecule neuroligin, because it was shown recently that postsynaptic expression of neuroligin is necessary and sufficient for presynaptic development at various central synapses (Scheiffele et al., 2000). It will be of interest to 
resolve whether neuroligin expression is in any way under the control of menin during central synaptogenesis.

In addition to the aforementioned role in synapse formation, menin may also serve important functions in other developmental processes. For instance, menin expression and subcellular localization are tightly regulated during the cell cycle, suggesting a role in cell division and cell growth (Kaji et al., 1999). Recent studies have demonstrated that other molecules with early developmental functions can also be involved in the control of neurite outgrowth and synapse formation. For instance, the Notch transmembrane receptor, which is involved in lateral specification of cellular identity during early embryonic development, provides an important stop signal for outgrowing cortical neurons (Sestan et al., 1999). Similarly, Wnt factors, which are well studied with respect to their roles in determining cell fate and embryonic patterning, control presynaptic maturation at developing cerebellar mossy fiber synapses and may also be involved in synaptic plasticity in the mature brain (Hall et al., 2000). Thus, the cooptation of early developmental factors may represent a common mechanism in the control of synapse formation and synaptic plasticity. Most of these factors are able to alter gene expression directly or indirectly, and the identification of target genes will be of particular importance for further understanding the molecular mechanisms underlying synapse formation.

\section{REFERENCES}

Agarwal SK, Guru SC, Heppner C, Erdos MR, Collins RM, Park SY, Saggar S, Chandrasekharappa SC, Collins FS, Spiegel AM, Marx SJ, Burns AL (1999) Menin interacts with the AP1 transcription factor JunD and represses JunD-activated transcription. Cell 96:143-152.

Altschul SF, Gish W, Miller W, Myers EW, Lipman DJ (1990) Basic local alignment search tool. J Mol Biol 215:403-410.

Arber S, Ladle DR, Lin JH, Frank E, Jessell TM (2000) ETS gene Er81 controls the formation of functional connections between group Ia sensory afferents and motor neurons. Cell 101:485-498.

Chandrasekharappa SC, Guru SC, Manickam P, Olufemi SE, Collins FS, Emmert-Buck MR, Debelenko LV, Zhuang Z, Lubensky IA, Liotta LA, Crabtree JS, Wang Y, Roe BA, Weisemann J, Boguski MS, Agarwal SK, Kester MB, Kim YS, Heppner C, Dong Q, Spiegel AM, Burns AL, Marx SJ (1997) Positional cloning of the gene for multiple endocrine neoplasia-type 1. Science 276:404-407.

Chang Q, Balice-Gordon RJ (2000) Highwire, rpm-1, and futsch: balancing synaptic growth and stability. Neuron 26:287-290.

Feng Z-P, Klumperman J, Lukowiak K, Syed NI (1997) In vitro synaptogenesis between the somata of identified Lymnaea neurons requires protein synthesis but not extrinsic growth factors or substrate adhesion molecules. J Neurosci 17:7839-7849.

Feng Z-P, Hasan SU, Lukowiak K, Syed NI (2000) Target cell contact suppresses neurite outgrowth from soma-soma paired Lymnaea neurons. J Neurobiol 42:357-369.

Guru SC, Goldsmith PK, Burns AL, Marx SJ, Spiegel AM, Collins FS, Chandrasekharappa SC (1998) Menin, the product of the MEN1 gene, is a nuclear protein. Proc Natl Acad Sci USA 95:1630-1634.

Guru SC, Prasad NB, Shin EJ, Hemavathy K, Lu J, Ip YT, Agarwal SK, Marx SJ, Spiegel AM, Collins FS, Oliver B, Chandrasekharappa SC (2001) Characterization of a MEN1 ortholog from Drosophila melanogaster. Gene 263:31-38.

Hall AC, Lucas FR, Salinas PC (2000) Axonal remodeling and synaptic differentiation in the cerebellum is regulated by WNT-7a signaling. Cell 100:525-535.

Hamakawa T, Woodin MA, Bjorgum MC, Painter SD, Takasaki M, Lukowiak K, Nagle G, Syed NI (1999) Excitatory synaptogenesis between identified Lymnaea neurons requires extrinsic trophic factors and is mediated by receptor tyrosine kinases. J Neurosci 19:9306-9312.
Kaji H, Canaff L, Goltzman D, Hendy GN (1999) Cell cycle regulation of menin expression. Cancer Res 59:5097-5101.

Kaji H, Canaff L, Lebrun JJ, Goltzman D, Hendy GN (2001) Inactivation of menin, a Smad3-interacting protein, blocks transforming growth factor type $\beta$ signaling. Proc Natl Acad Sci USA 98:3837-3842.

Khodaei S, O'Brien KP, Dumanski J, Wong FK, Weber G (1999) Characterization of the MEN1 ortholog in zebrafish. Biochem Biophys Res Commun 264:404-408.

Marek KW, Ng N, Fetter R, Smolik S, Goodman CS, Davis GW (2000) A genetic analysis of synaptic development: pre- and postsynaptic dCBP control transmitter release at the Drosophila NMJ. Neuron 25:537-547.

Markowitz SD, Roberts AB (1996) Tumor suppressor activity of the TGF- $\beta$ pathway in human cancers. Cytokine Growth Factor Rev 7:93-102.

Maruyama K, Tsukada T, Hosono T, Ohkura N, Kishi M, Honda M, Nara-Ashizawa N, Nagasaki K, Yamaguchi K (1999) Structure and distribution of rat menin mRNA. Mol Cell Endocrinol 156:25-33.

Maruyama K, Tsukada T, Honda M, Nara-Ashizawa N, Noguchi K, Cheng J, Ohkura N, Sasaki K, Yamaguchi K (2000) Complementary DNA structure and genomic organization of Drosophila menin. Mol Cell Endocrinol 168:135-140.

Nakai K, Kanehisa M (1992) A knowledge base for predicting protein localization sites in eukaryotic cells. Genomics 14:897-911.

Ozaki M, Sasner M, Yano R, Lu HS, Buonanno A (1997) Neuregulin- $\beta$ induces expression of an NMDA-receptor subunit. Nature 390:691-694.

Ratziu V, Lalazar A, Wong L, Dang Q, Collins C, Shaulian E, Jensen S, Friedman SL (1998) Zf9, a Kruppel-like transcription factor upregulated in vivo during early hepatic fibrosis. Proc Natl Acad Sci USA 95:9500-9505

Rudnicki MA, Jaenisch R (1995) The MyoD family of transcription factors and skeletal myogenesis. BioEssays 17:203-209.

Sanes JR, Lichtman JW (1999) Development of the vertebrate neuromuscular junction. Annu Rev Neurosci 22:389-442.

Schaefer AM, Hadwiger GD, Nonet ML (2000) Rpm-1, a conserved neuronal gene that regulates targeting and synaptogenesis in C. elegans. Neuron 26:345-356.

Schaeffer L, Duclert N, Huchet-Dymanus M, Changeux JP (1998) Implication of a multisubunit Ets-related transcription factor in synaptic expression of the nicotinic acetylcholine receptor. EMBO J 17:3078-3090.

Scheiffele P, Fan J, Choih J, Fetter R, Serafini T (2000) Neuroligin expressed in nonneuronal cells triggers presynaptic development in contacting axons. Cell 101:657-669.

Sestan N, Artavanis-Tsakonas S, Rakic P (1999) Contact-dependent inhibition of cortical neurite growth mediated by notch signaling. Science 286:741-746.

Stewart C, Parente F, Piehl F, Farnebo F, Quincey D, Silins G, Bergman L, Carle GF, Lemmens I, Grimmond S, Xian CZ, Khodei S, Teh BT, Lagercrantz J, Siggers P, Calender A, Van de Vem V, Kas K, Weber G, Hayward N, Gaudray P, Larsson C (1998) Characterization of the mouse Men1 gene and its expression during development. Oncogene 17:2485-2493.

Syed NI, Winlow W (1991) Respiratory behaviour in the pondsnail Lymnaea stagnalis. II. Neuronal elements of the central pattern generator. J Comp Physiol [A] 169:A559-A568.

Syed NI, Bulloch AGM, Lukowiak K (1990) In vitro reconstruction of the respiratory central pattern generator of the mollusk Lymnaea. Science 250:282-285.

Syed NI, Richardson P, Bulloch AGM (1996) Ciliary neurotrophic factor, unlike nerve growth factor, supports neurite outgrowth but not synapse formation by adult Lymnaea neurons. J Neurobiol 29:293-303.

Van Minnen J, van Kesteren RE (1999) Tracking mRNA in axons and dendrites. In: Modern techniques in neuroscience research (Windhorst U, ed), pp 57-88. Heidelberg: Springer.

Wong RG, Hadley RD, Kater SB, Hauser GC (1981) Neurite outgrowth in molluscan organ and cell cultures: the role of conditioning factor(s). J Neurosci 1:1008-1021.

Woodin MA, Hamakawa T, Takasaki M, Lukowiak K, Syed NI (1999) Trophic factor-induced plasticity of synaptic connections between identified Lymnaea neurons. Learn Mem 6:307-316.

Zhang F, Endo S, Cleary LJ, Eskin A, Byrne JH (1997) Role of transforming growth factor- $\beta$ in long-term synaptic facilitation in Aplysia. Science 275:1318-1320. 